\title{
Evaluating the Mechanical Characteristics of Al/SiC Metal Matrix Composites (MMC) Using Infrared Thermography Images
}

\author{
By R. Ruban Blessed Singh*, Dr. T. Sasikumar*
}

*Centre for Research, Department of Mechanical Engineering, Lord Jegannath college of Engineering and Technology Ramanatichanputur, Kanyakumarai District- 629 402, Tamilnadu, India, rubansin@yahoo.co.in, sasikumar.t2000@gmail.com

\begin{abstract}
The aim of the study is to characterize the composite by visualizing the different stages of deformation on the tensile specimen of $\mathrm{Al} / \mathrm{SiC}$ metal matrix composite using Infrared thermography technique. Infrared thermography is a Non-contact technique to record the surface temperature distribution. Infrared thermography is a powerful non-destructive evaluation tool for online monitoring the different stages of deformation and to predicting the exact region of fracture with respect to temperature variations. The Infrared images are acquired from the specimens for the material characterization. It is a high sensitive Nondestructive testing technique for detecting the active microscopic events the material. Al/SiC composites has high strength, high resistance to wear and low weight properties make them demand full in many industrials applications such as marine, electronic packages, cost-effective solutions for many thermal management problems, automotive and aerospace industries.

In this present study, SiC (220 mesh) particulates reinforced in the AL6061-T6 alloy matrix and fabricated the composites by low cost stir casting technique with $10 \%$ of SiC and $90 \%$ of Aluminum alloy by weight. The tensile tests was conducted with displacement control and a constant crosshead speed of $2 \mathrm{~mm} / \mathrm{min}$. Studies were conducted to determine the tensile properties, modulus of elasticity, ultimate tensile strength, fracture load, yield point and variation of temperature of the specimens. Interpretation of heat emission signals acquired from the Al/SiC MMCs specimens during proof testing with the Infrared thermography images may give a better platform for the prior prediction of the ultimate strength of the specimens while tensile loading. The experimental result reveals that the ultimate temperature rise and the rate of temperature rise is having a good correlation with the deformation behavior of the $\mathrm{Al} / \mathrm{SiC}$ materials during tensile loading. Also Success of this proposed research work would be a good feed for the composite industries at which the characterization is very much essential.
\end{abstract}

Keywords: Metal Matrix Composite, Stir Casting Technique, Tensile Deformation Testing, Infrared Thermography Imaging Techniques and Fracture mode characterization

\section{INTRODUCTION}

Infrared thermography is the science of acquisition and analysis of thermal information by using non-contact thermal imaging devices [1]. Infrared thermography is a Non-contact technique to record the surface temperature distribution. Infrared thermography is a powerful non-destructive evaluation tool for on-line monitoring the different stages of deformation and predicting the exact region of fracture is anticipated. The Infrared Images are acquired from the specimens for characterization. It is a high sensitivity potential Non-destructive testing technique for detecting active microscopic events inside the material [2].

The historical revolution of thermography is, In 1953 the first step towards accurate measurement of temperature was achieved and designed the first glass thermometer by Galileo. In 1800, German scientist William Herschel (1738-1822) discovered the existence of IR rays. In 1829 Nobili invented the first thermocouple. In 1833 Melloni made the first thermopile by connecting many thermocouples. In 1840 Hershel's son John produced the first IR image using evaporograph. In 1880 the bolometer was invented by A. Longley perfected by Abbot. In 1900 Max Planck theory of radiation clarified Herchel's experiment. In 1917 World War 1 brought the first photoconductive detector. In 1940 and 1950 Indium antimonide detectors followed and mercury tallium telluride detectors [2].

In 1960 and 1970 the first IR cameras became commercially available. Among the world largest commercial providers, Inframetrics was set up in 1975 in the United States, while Agema of Sweden marketed the first commercial infrared camera system in 1965. Other companies also emerged during these years. Early IR cameras used pyroelectric tube technology. Pyroelectric tubes are thermal detectors similar to vidicon TV cameras but with an IR-transmitting face plate and specific pyroelectric target material such as riglyceride sulfate. Images are produced by an electron beam scanning the target. Other early infrared cameras contained only a single detector, and image generation was made possible by a rotating electro-optical system. On some models, during the retrace, it was possible for the detector to be in the viewing corridor of an internal blackbody, a calibrated source of infrared radiation. This feature enables direct calibration of the output signals. For this reason, such cameras are often referred to as scanning radiometers. A detector known as SPRITE (signal processing in the element) was developed in the United Kingdom by Elliot at the Royal Signal and Radar Establishment, makes it possible to circumvent some of the disadvantages of scanning radiometers. ie. Signal is integrated on the focal plane itself, reducing the noise level and timing considerations [2].

In the early 1980 a small revolution occurred in the IR community with the development of first focal plane array IR cameras. FPA are similar in structure to solid state CCD (charge coupled device) video cameras but are sensitive in the IR. Basically, an FPA (matrix of detectors) camera comprises a chip associated with electronics (amplifiers, analog to digital converters). Since no scanning mechanism is needed for image formation, these cameras offer several advantages, such as higher spatial resolution, less noise, and more rugged structure. Moreover, direct digital output suppresses the need for TV compatible signals, thus enabling acquisition of fast thermal events [2]. 
Full image acquisition at over $400 \mathrm{~Hz}$ and sub image acquisition at over $30 \mathrm{~Hz}$ are now available. A drawback is the uncalibrated output signals since without a scanning mechanism, no internal blackbody is seen as in scanning radiometers. In the late 1970 and early, with the broader availability of large integrated circuit (IC) fabrication technology, it was possible to make large uncooled bidimensional arrays based on pyroelectric effects thermopiles and microbolometers. IR has a long history with succeeding milestones for always improved performance, now combined with more complex and powerful signal processing techniques packaged in always smaller computers and processors [2].

Active Infrared Thermography Technique (IRT) gives better measurement quality, efficiency and repeatability for the detection of surface defects such as cracks and corrosion in forged metallic materials than the traditional NDT methods such as magnetic particle inspection and Penetration test. [3]. Active IRT is non-contact, fast, very good accuracy measurement, does not involve complicated data analysis, and also gives for time constant temperature decay values increase with reducing air-gap of Aluminum outer hollow cylinder and the solid SS insert. This technique is used for determination of annular gap in nuclear pins, fuel to clad gap of nuclear reactor fuels and detection of misalignment of concentric machineries [4]

Characterization on AISI 316 Steel can be done by IRT Technique by observing the temperature gradient on plastic flow and transient exothermic changes that takes place in the various stages of tensile deformation [5]. Characterization and preparation of Al2014 alloy with SiC particle inclusion can be done by micro structural surface examination observing the hardness of the Al alloy improved significantly by addition of SiC particle, density also increased almost linearly with the weight fraction of particles, no interface porosity in SiCp distributions is homogeneous, Porosity level increased slightly with increasing particulate content and decreasing with increasing particle size, tool life decreased with increasing the cutting speeds, wear resistance is better performance than those of the other tools [6]. Characterization the mechanical properties like as tensile strength, modulus of elasticity and hardness using tensile test by Preparation of LM6 alloy with SiC particle and SEM to observe the MMC tensile properties and hardness of the cast composites increases with the increasing the weight percentage of SiC particulates in the matrix metal. The SEM images reveals that the SiC particles are uniformly distributed throughout the MMC castings [7].

The tensile test on 6061-T6 aluminum matrix composite reinforced SiC particulates is used to predicting the residual fatigue life by fatigue and Acoustic Emission test to observe the exponential increase in strain, occurred when the material is in the plastic regime and the crack initiation period dominated the life of the composite in the high cycle fatigue regime and residual tensile strengths of the material not change [8] .

The failure zone of a material can be predicted and also time of strain localization during a tensile deformation by using IRT technique [9].An active IRT technique is used in order to monitor the spatial and temporal temperature distribution for measuring the thermal diffusivity to identify the time [10]. The monotonic tensile test and fatigue test on Aluminum alloy AA7075 and Silicon Carbide ( $\mathrm{SiC}$ ) particle reinforced A359 Al alloy reveals the mechanical damage process in structure of the material using thermography and Acoustic Emission (AE) technique is used to assess the crack growth damage rate and early prediction of upcoming catastrophic failure [11].

The fatigue test on C70 annealed steel is used to characterize the dynamic properties of materials like the temperature on the external surface, zone of greatest stress, indication of the zone where failure from fatigue will occur based on increase in temperature when the stress reaches above the fatigue limits, due to the production of plastic energy [12]. Detection of damage growth, critical damage states, cracking, changes in stiffness, degradation rate, surface temperature to identify the local high temperature regions that corresponded to damage during fatigue and cyclic loading in an anisotropy polymeric composite materials, using the IRT technique [13].

Predictive precautions condition in industries, like identifying the failure components at the earlier stage of fault development that can be the cause for a major breakdown at the later stage can be avoided, material characterization, surveillance and healthcare like detection of breast cancer and vascular disorders [14].

An objective of the thermography is to detect the temperature differences to determine the absolute temperature, to view thermal profiles and to detect temperature loss. Infrared thermography is a technique for the radiometric measurement of the surface temperature using infrared sensors, and it is divided into active thermography and passive thermography. Active thermography requires an external heat source and is used for measuring properties in steady state and transient regime, while the latter does not need a source and measures the permanent conditions. The very important four active methods are pulsed thermography, Step heating (Long pulse), Lock-in thermography and vibro thermography. Passive thermography, abnormal temperature profiles indicate a potential problem, and a key term is temperature difference with respect to a reference, often referred to as the delta-T value or the hot spot.

Advantages of thermography is Non-Contact, Non-Intrusive, Can work at a distance, Fast and Reliable, Portable Convincing Results, Global examination of part, Only one side access is required for the examination, Real Time inspection, not very sensitive to part geometry, well suited for large surfaces, Apply for all composite structure and materials even porous.

Applications of thermography is condition based maintenance, R\&D, Medical and veterinary, Quality control and process monitoring, Non-destructive testing, others Electrical maintenance, Buildings, Furnaces and boilers, Mechanical, friction, Fluid flow problems, Tanks and vessels. Aluminum matrix reinforced with silicon carbide particle $(\mathrm{mmc})$ has high strength, high resistance to wear and low weight Properties make demand full in many applications in the production, aero and electronics industries. 


\section{Objective of the Research}

Outcome of these literature surveys reveals that there is no much research has been recorded on Al-SiC MMC material characterization with the help of infrared thermography.

It is well-known that the composite materials are very widely used in automotive industries due to its good strength to weight ratio. On the other hands, the failure of the composite may be in catastrophic mode during utilization. Hence Structural Integrity Evaluation is badly in need on MMC materials. Interpretation of heat emission signals acquired from the Al/SiC MMCs specimens during proof testing with the Infrared thermography images may give us better platform for the prior prediction of the ultimate strength of the specimens while tensile loading.

It is a significant method to do the failure characterization of the Al/Sic Metal Matrix Composite the various failure modes that is taking on the metal matrix composite like particle cracking, matrix cavitation, interfacial bonding, ductile failure by the nucleation, growth and coalescence of voids within the metallic matrix and debonding of the interface between the matrix and the reinforcement during loading can be analyzed by using the active thermography.

Infrared Camera fixed in front of the MMC couples will give the signals according to the physical structural changes taking place inside the specimen while it is tensile loaded. By analyzing the color codes of the Infrared Camera signals, we can very clearly measure the degradation of Al/SiC MMCs.

\section{Experimental Procedure}

\subsection{Material Preparation}

A stir casting system has been developed by coupling motor with gearbox and a stainless steel stirrer. The temperature was controlled by the control unit. Melting was carried out in a graphite crucible in an oil-fired furnace. Fig.1 shows the schematic diagram shows the Charge preparation of Al/Sic metal matrix composite in the Stir Casting Process.

Ingots of aluminum were preheated at $300^{\circ} \mathrm{C}$ to $400^{\circ} \mathrm{C}$ for 4 hours before melting and mixing the SiC particles were preheated at $1000^{\circ} \mathrm{C}$ for 1 to 3 hours to make their surfaces oxidized. The furnace temperature was first raised above the liquidus to melt the ingots completely and was then cooled down just below the liquidus to keep the slurry in a semi-solid state. At this stage the preheated SiC particles were added and mixed manually. Manual mixing was used to avoid the uneven mixing of particles in the semi-solid alloy.

After the thorough mix up the composite slurry was reheated to a fully liquid state and then automatic mechanical mixing was carried out for about 5 minutes at a normal stirring rate of $600 \mathrm{rpm}$.In the final mixing process, the furnace temperature was controlled within $760 \pm 10^{\circ} \mathrm{C}$ and poured in the Green sand mould prepared according to the specifications for tensile deformation test.The composition of alloys and matrix reinforcement materials are given in Table 1.

Table-1.Details of AL/SiC Metal Matrix Composites volume fraction

\begin{tabular}{|c|c|c|}
\hline Materials & AL6061-T6 & SiC \\
\hline Matrix & $\begin{array}{c}\text { AL6061 T6 } \\
\text { Aluminum Alloy }\end{array}$ & \\
\hline Reinforcement & & $\begin{array}{l}20 \text { Vol \% SiC } \\
\text { Particulate }\end{array}$ \\
\hline Particle Size & - & 220 mesh \\
\hline Process & $\begin{array}{c}\text { Stir casting } \\
\text { Melting Al at } 800^{\circ} \mathrm{C}\end{array}$ & $\begin{array}{c}\text { Heating SiC at } \\
1000^{\circ} \mathrm{C}\end{array}$ \\
\hline Volume fraction & $90 \%$ & $10 \%$ \\
\hline $\begin{array}{l}\text { Stirring Speed } \\
\text { rate }\end{array}$ & \multicolumn{2}{|c|}{$600 \mathrm{rpm}$} \\
\hline
\end{tabular}

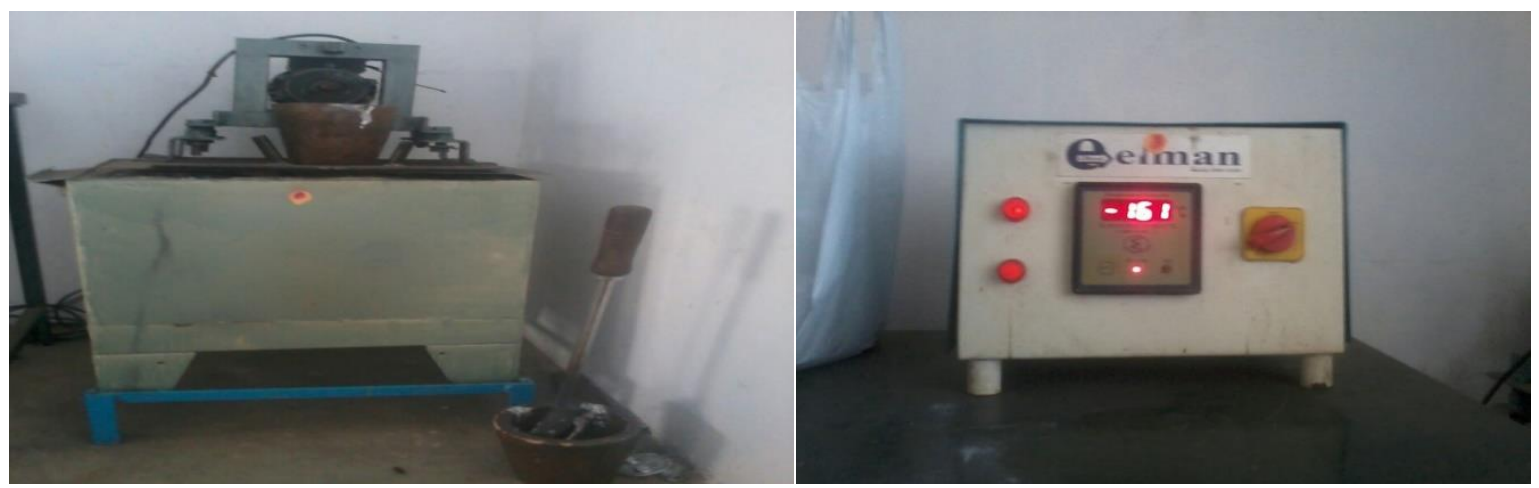

Fig.1. Schematic diagram of Stir Casting Process

The moulded sheet was machined to get dog-bone specimen for tensile test. Metal matrix composite coupons with the dimension $203.2 \times 38.1 \times 12.7 \mathrm{~mm}$ were fabricated. The thickness of the coupon is $12.7 \mathrm{~mm}$. Fig.2. Shows 
the detailed dimensions of Al/Sic metal matrix specimens. Ten numbers of specimens were prepared according to ASTM standard B577M-14.(1) Fig-3 shows schematic diagram of finished Al/Sic metal matrix composite tensile specimens.

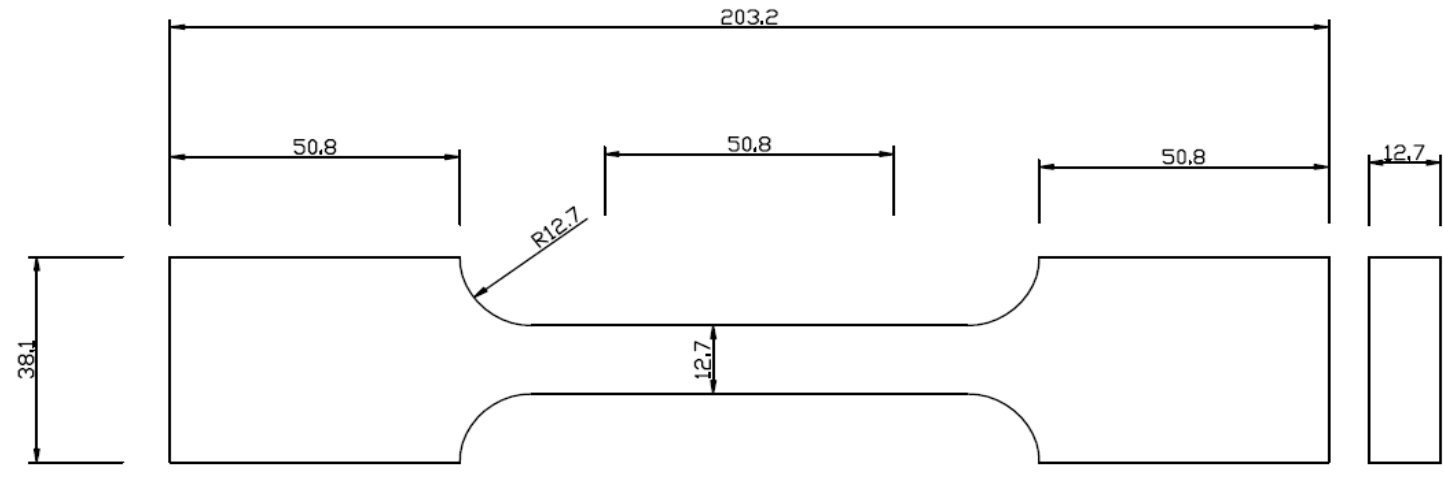

ALL DIMENSIONS ARE IN " MM "

Fig.2. Line diagram of Al/Sic metal matrix specimens.

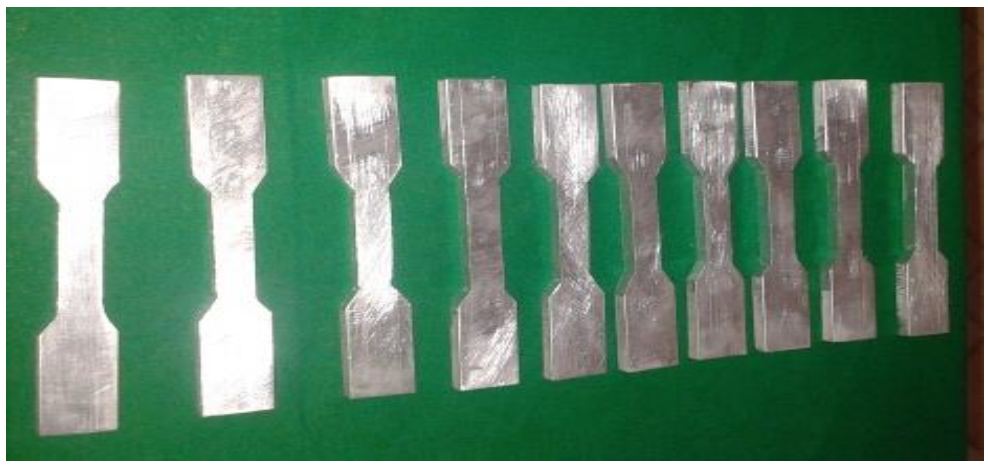

Fig-3 Al/Sic metal matrix composite tensile specimen

\subsection{Tensile testing procedure}

Initially the outer surfaces of the aluminum silicon carbide coupon were black painted to enhance the emissivity. In fact the heat waves diffuses through aluminium very fast. The schematic of external surface of the outer Al-SiC Specimen is black painted to enhance the emissivity is shown in Fig. 4. Al/SiC MMCs Specimen to camera distance was maintained at approximately $450 \mathrm{~mm}$ in all the coupons.

The tensile tests were conducted using the HUNG TA - HT 2402 Series, 25 Ton capacity Servo controlled screw driven type UTM with data acquisition facility.

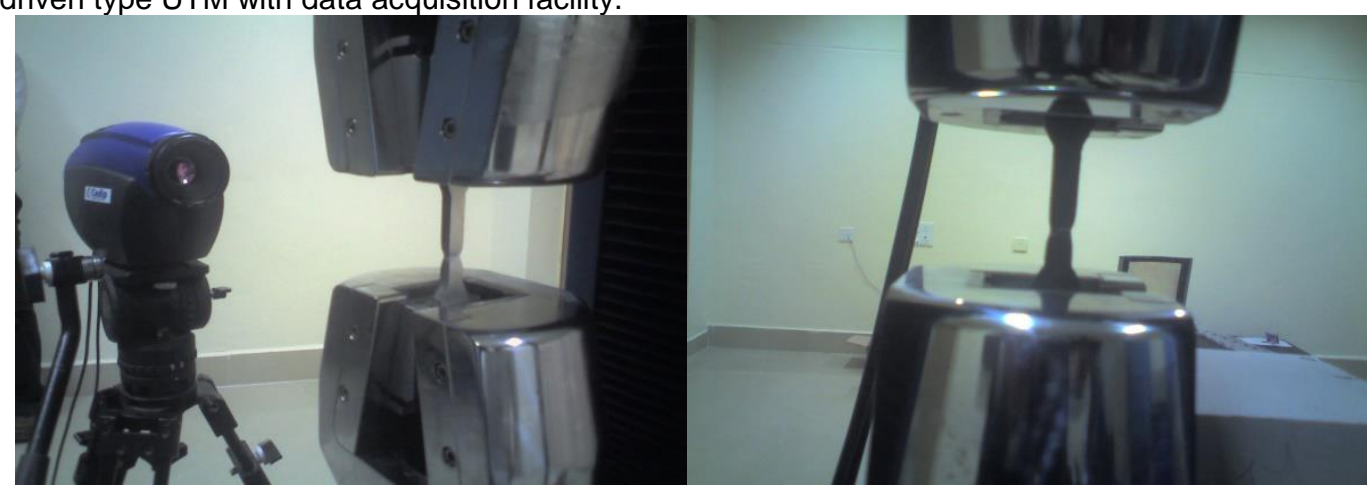

Fig:4 Tensile test setup

During the tensile deformation testing, thermal images were acquired up to 294.5s using a CEDIP SILVER 420 series infrared camera. This camera has indium antimonide (InSb) semiconductor with a focal plane array (FPA) windowing of $320 \times 256$ elements. The spectral range and waveband of the camera is 3.6-5.1 $\mu \mathrm{m}$, a digital frame rate of $170 \mathrm{~Hz}$. The pixel resolution of IR camera was $25 \mu \mathrm{m}$ and pixel pitch was $30 \mu \mathrm{m}$. The measurement of Standard Camera Calibration Range was $5^{\circ} \mathrm{C}$ to $1000^{\circ} \mathrm{C}$. Interfaces digital data output was USB 14 bit and filter options was Filter wheel with 4 slots.

The Al-SiC MMC specimens were mounted vertically inside UTM grippers at top and bottom. The environmental influences are controlled by providing the closed air conditioned room for tests. The instrument was provided with a front visible opening which enabled the continuous monitoring of temperature variations. The 
photograph of the experimental setup is shown in Fig. 5. The choice of the initial temperature was based on temperature decay time, transverse dimensions and thermal diffusivity of the object under consideration.

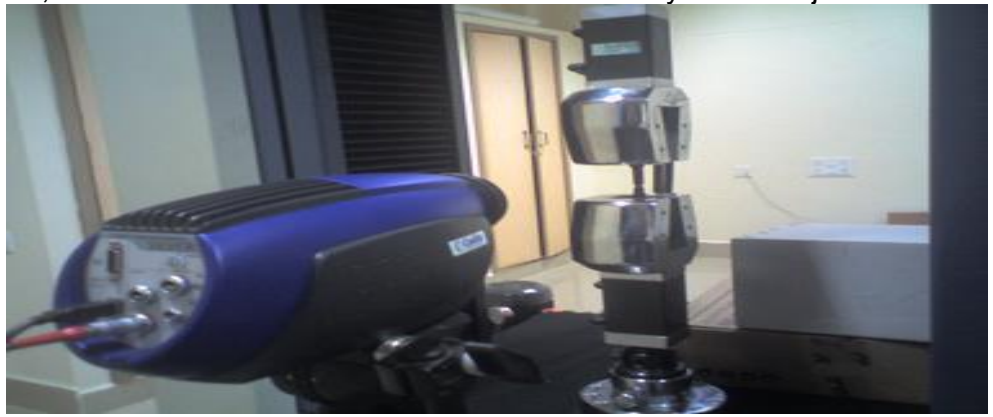

Fig:5 Test setup with IR Camera

During the analysis selected mean surface temperature and time were taken for studying the failure evolution of the specimens as a function of time. The experimental technique is based on the time constant of temperature decay and not on absolute temperature contrast. The test Al-SiC MMC specimens were gradually loaded with the universal testing machine of 25 ton capacity, While Infrared camera was focused and monitored heat waves from gauge length (middle) of the specimen along with the corresponding load were recorded. The load was applied till the specimen fails. The acquired thermal images were stored in a personal computer (PC) and later analyzed using ALTAIR software. This same procedure was repeated for all the ten specimens. However the result of only one specimen has been discussed as below.

\section{RESULT}

By this research work that would be very useful of metal matrix composite structure to characterize and visualize different stages of failure deformation with predict the exact region of fracture of Al/SiC metal matrix composite specimen may have to be understood properly. From $0 \mathrm{sec}$ to $250 \mathrm{sec}$ time duration with interval of 50 secs, the displacement of the Al/SiC specimen-1 varies from 0 to $8.32 \mathrm{~mm}$ and the specimen's load ranges from 0 to $22.3 \mathrm{KN}$. During these time intervals, no changes have been noticed in the infrared images, but with the temperature $26.06^{\circ} \mathrm{C}$. Fig-6. Shows Sequence of Infrared thermal images for a constant crosshead speed 2 $\mathrm{mm} / \mathrm{sec}$ from $0 \mathrm{sec}$ to $200 \mathrm{sec}$ with time interval of $50 \mathrm{sec}$ respectively.

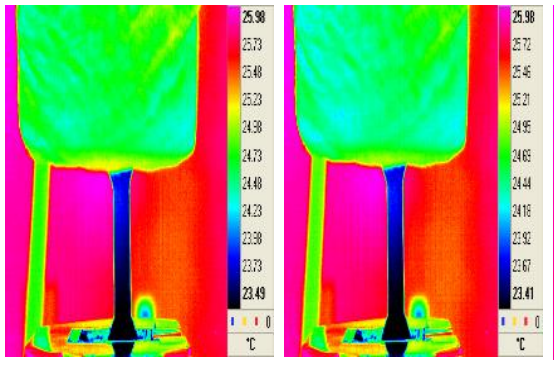

(a) $t=0$ sec (b) $t=50 \mathrm{sec}$

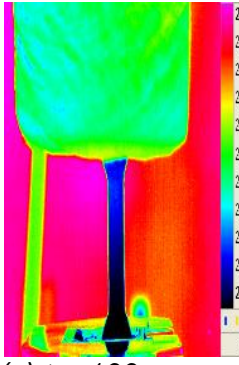

(c) $t=100 \mathrm{sec}$

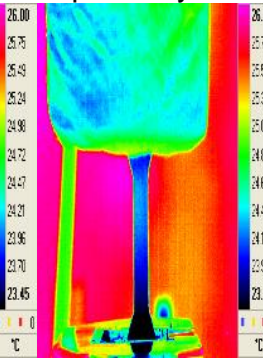

(d) $t=150 \mathrm{sec}$

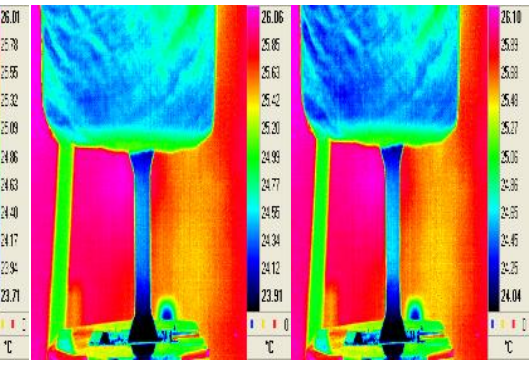

(e) $t=200 \mathrm{sec}$ (f) $t=250 \mathrm{sec}$

Fig-6. Sequence of Infrared thermal images for a constant crosshead speed $2 \mathrm{~mm} / \mathrm{sec}$ from 0 sec to $250 \mathrm{sec}$ with time interval of 50 sec respectively

From $255 \mathrm{sec}$ to $290 \mathrm{sec}$ time duration with the time interval of $5 \mathrm{secs}$, the displacement of the specimen -1 varies from 8.4 to $9.6 \mathrm{~mm}$ and the specimen's load ranges from 22.3 to $22.5 \mathrm{KN}$. During this time period, the specimen has been stretched while looking at the infrared images, but with the temperature $26.13^{\circ} \mathrm{C}$. Fig-7. Shows sequence of Infrared thermal images for a constant crosshead speed $2 \mathrm{~mm} / \mathrm{sec}$ start necking from 250 sec to $290 \mathrm{sec}$ with time interval of $5 \mathrm{sec}$.

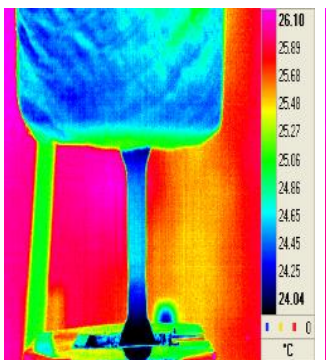

(a) $t=250 \mathrm{sec}$

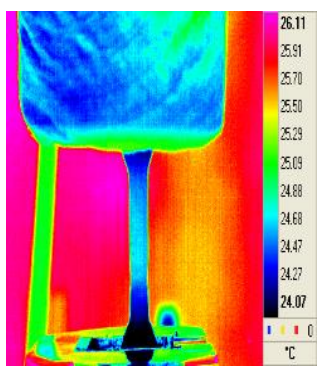

(b) $t=255 \mathrm{sec}$

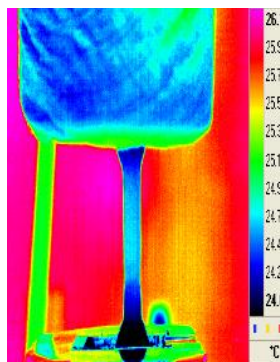

(c) $t=260 \mathrm{sec}$

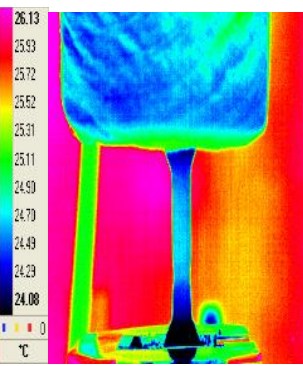

(d) $t=265 \mathrm{sec}$

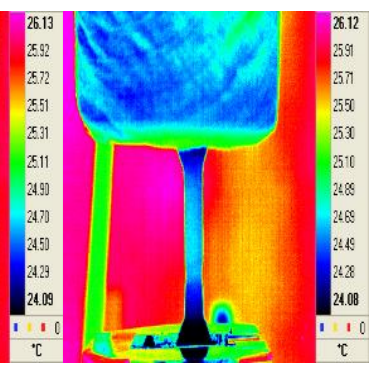

(e) $t=270 \mathrm{sec}$ 


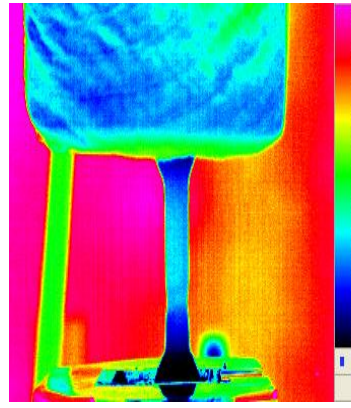

(f) $t=275 \mathrm{sec}$

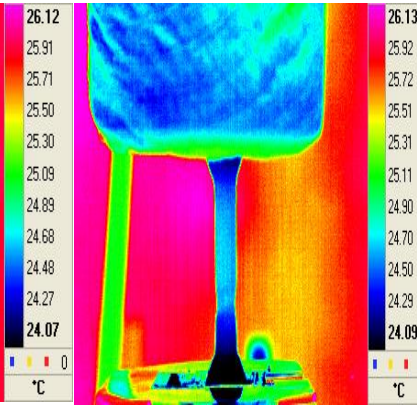

(g) $t=280 \mathrm{sec}$

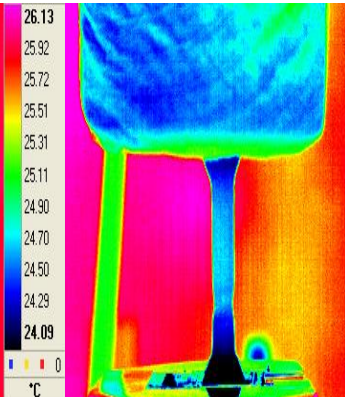

(h) $t=285 \mathrm{sec}$

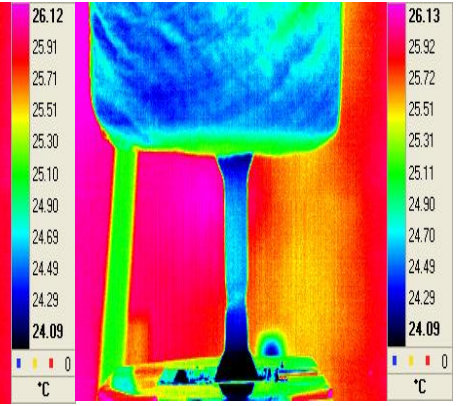

(i) $t=290 \mathrm{sec}$

Fig-7. Sequence of Infrared thermal images for a constant crosshead speed $2 \mathrm{~mm} / \mathrm{sec}$ start necking from $250 \mathrm{sec}$ to $290 \mathrm{sec}$ with time interval of $5 \mathrm{sec}$ respectively

From $290.5 \mathrm{sec}$ to $294 \mathrm{sec}$ time duration with the time interval of $0.5 \mathrm{secs}$, the displacement of the specimen-1 varies from 9.6 to $9.7 \mathrm{~mm}$ and the specimen's load ranges from 22.5 to $22.602 \mathrm{KN}$. During this time period, the specimen looks highly necking while looking at the infrared images and the temperature $26.15^{\circ} \mathrm{C}$. Fig8. Shows Sequence of Infrared thermal images for a constant crosshead speed $2 \mathrm{~mm} / \mathrm{sec}$ necking stage from $290.5 \mathrm{sec}$ to $294 \mathrm{sec}$ with time interval of $0.5 \mathrm{sec}$ respectively.

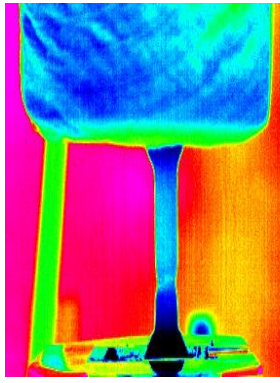

(a) $t=290.5 \mathrm{sec}$

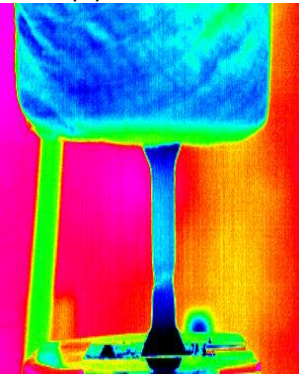

(e) $t=292.5 \mathrm{sec}$

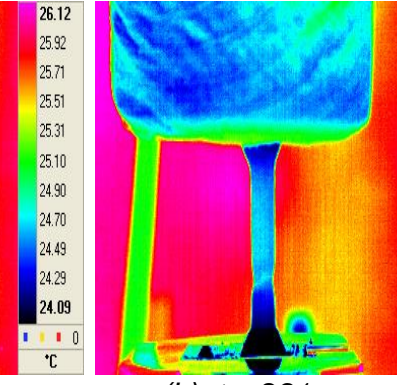

(b) $t=291 \mathrm{sec}$
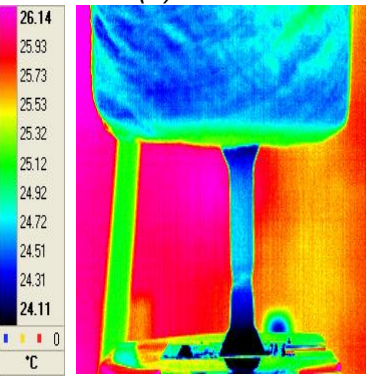

(f) $t=293 \mathrm{sec}$

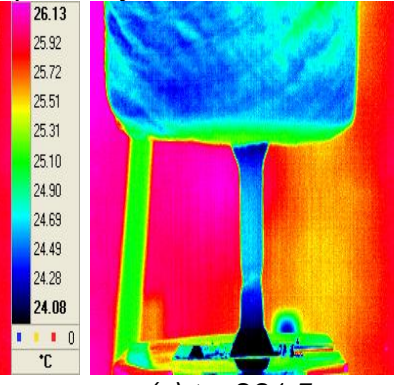

(c) $t=291.5 \mathrm{sec}$
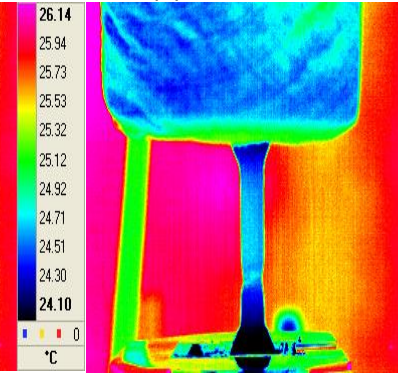

(g) $t=293.5 \mathrm{sec}$

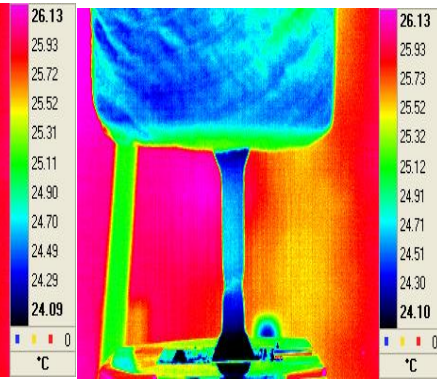

(d) $t=292 \mathrm{sec}$

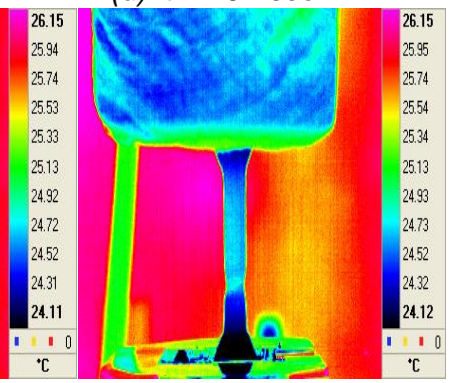

(h) $t=294 \mathrm{sec}$

Fig-8. Sequence of Infrared thermal images for a constant crosshead speed $2 \mathrm{~mm} / \mathrm{sec}$ necking stage from 290.5 sec to $294 \mathrm{sec}$ with time interval of $0.5 \mathrm{sec}$ respectively

From $294.1 \mathrm{sec}$ to $294.4 \mathrm{sec}$ time duration with the time interval of $0.1 \mathrm{secs}$, the displacement of the specimen varies from 9.76412 to $9.76099 \mathrm{~mm}$ and the specimen's load ranges from 22.602 to $22.608 \mathrm{KN}$. During this time period, the specimen looks highly necking while looking at the infrared images and the temperature. Fig-9. Shows Sequence of Infrared thermal images for a constant crosshead speed $2 \mathrm{~mm} / \mathrm{sec}$ up to fracture from $294.1 \mathrm{sec}$ to $294.5 \mathrm{sec}$ with time interval of $0.1 \mathrm{sec}$ respectively.

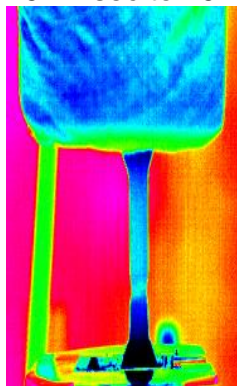

(a) $t=294.1 \mathrm{sec}$

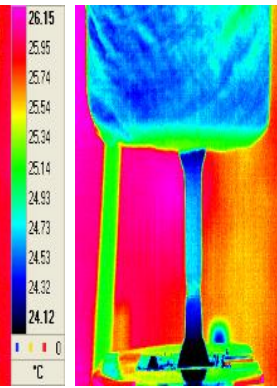

(b) $t=294.2 \mathrm{sec}$

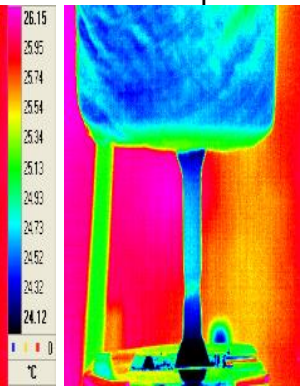

(c) $t=294.3 \mathrm{sec}$

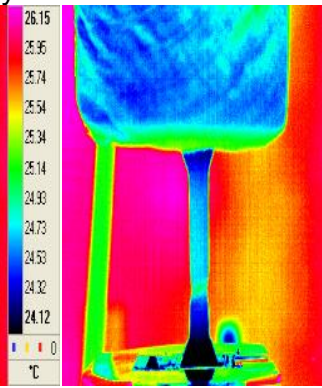

(d) $t=294.4 \mathrm{sec}$

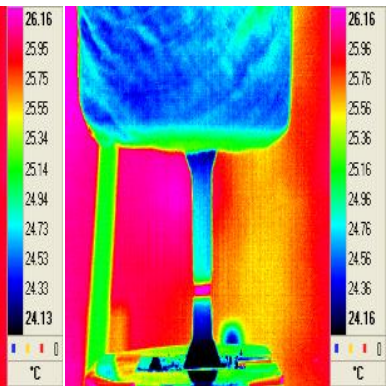

(e) $t=294.5 \mathrm{sec}$

Fig-9 Sequence of Infrared thermal images for a constant crosshead speed $2 \mathrm{~mm} / \mathrm{sec}$ up to fracture from 294.1 sec to $294.5 \mathrm{sec}$ with time interval of $0.1 \mathrm{sec}$ respectively

Table:2. Shows summary of results between Load vs displacement with time interval $50,5,0.5,0.1 \mathrm{sec}$ respectively during tensile deformation testing.Fig-10. Shows graphs have been plotted between Temperature Vs Time Failure load for complete time interval range up to $293.8 \mathrm{sec}$. Fig-11. Shows graphs have been plotted between Load Vs Time Failure load for complete time interval range up to $294.5 \mathrm{sec}$ Table: 3 . Shows Summary of 
results between fracture load vs temperature during tensile deformation testing with time interval 50 sec. Table: 4 . Summary of results between Stress vs Strain with Load. Fig: 12 shows Graphs have been plotted between Temperature Vs Time Failure load for complete time interval range of 0- $294.6 \mathrm{sec}$. Fig:13. Shows graphs have been plotted between stress vs strain diagram of Al/SiC specimen upto Failure load. Table: 5 shows summary of results during tensile deformation testing with actual and Graphical method. It is found that the failure load for specimen-1 is $22.608 \mathrm{KN}$, elastic yield point $21.2 \mathrm{KN}$, Ultimate tensile strength (UTS) $22.6 \mathrm{KN}$ and the fracture load is $15.1 \mathrm{KN}$. When the specimen breaks, the temperature becomes nearly $30.06^{\circ} \mathrm{C}$.

Table:2. Summary of results between Load vs displacement with time interval 50,5,0.5,0.1 sec respectively during tensile deformation testing

\begin{tabular}{|c|c|c|c|c|c|}
\hline \multirow[t]{2}{*}{ Load (KN) } & \multicolumn{4}{|c|}{$\begin{array}{l}\text { Time Interval } \\
\quad(\mathrm{Sec})\end{array}$} & \multirow[t]{2}{*}{$\begin{array}{l}\text { Displacement } \\
(\mathrm{mm})\end{array}$} \\
\hline & 50 & 5 & 0.5 & 0.1 & \\
\hline 0.084803 & 0 & & & & 0 \\
\hline 10.13189 & 50 & & & & 1.65837 \\
\hline 17.05153 & 100 & & & & 3.32743 \\
\hline 20.23642 & 150 & & & & 4.99608 \\
\hline 21.58848 & 200 & & & & 6.66508 \\
\hline 22.30041 & 250 & & & & 8.32437 \\
\hline 22.35307 & & 255 & & & 8.48659 \\
\hline 22.403 & & 260 & & & 8.64864 \\
\hline 22.4454 & & 265 & & & 8.81091 \\
\hline 22.48028 & & 270 & & & 8.97294 \\
\hline 22.51721 & & 275 & & & 9.13523 \\
\hline 22.5473 & & 280 & & & 9.29718 \\
\hline 22.56303 & & 285 & & & 9.45956 \\
\hline 22.57807 & & 290 & & & 9.62153 \\
\hline 22.58013 & & & 290.5 & & 9.6376 \\
\hline 22.58149 & & & 291 & & 9.65407 \\
\hline 22.58354 & & & 291.5 & & 9.67062 \\
\hline 22.58491 & & & 292 & & 9.68674 \\
\hline 22.58765 & & & 292.5 & & 9.70294 \\
\hline 22.59038 & & & 293 & & 9.71908 \\
\hline 22.5938 & & & 293.5 & & 9.7352 \\
\hline 22.60269 & & & 294 & & 9.75137 \\
\hline 22.60269 & & & & 294.1 & 9.76412 \\
\hline 22.60338 & & & & 294.2 & 9.75451 \\
\hline 22.60543 & & & & 294.3 & 9.75764 \\
\hline 22.60817 & & & & 294.4 & 9.76099 \\
\hline
\end{tabular}

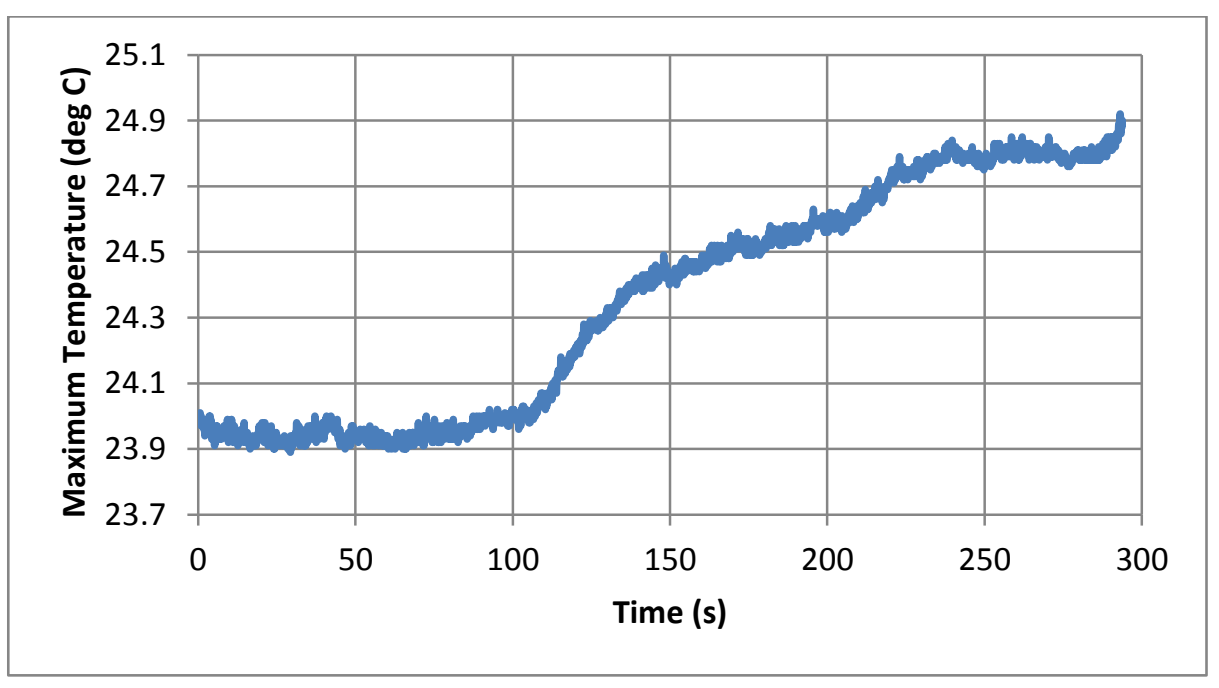

Fig-10. Temperature Vs Time Failure load for complete time interval range up to $293.8 \mathrm{sec}$ 


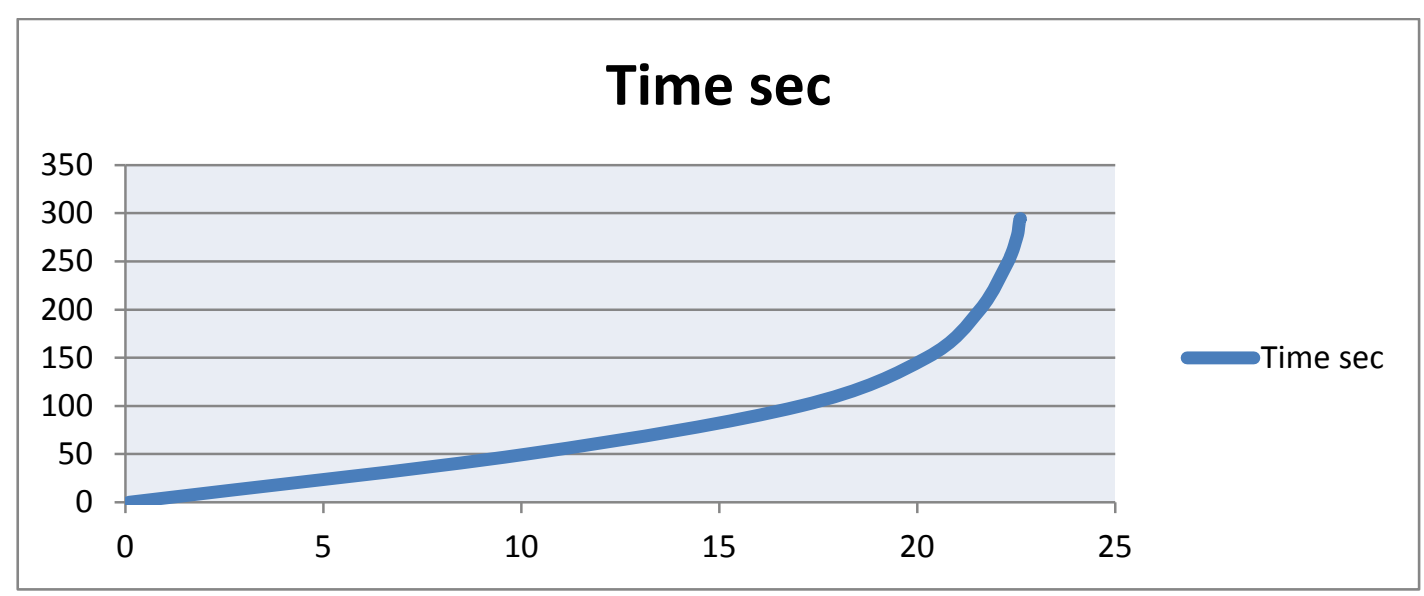

Fig-11. Load Vs Time Failure load for complete time interval range up to $294.5 \mathrm{sec}$

Table: 3.Summary of results between fracture load vs temperature during tensile deformation testing with time interval $50 \mathrm{sec}$

\begin{tabular}{|c|c|c|}
\hline Sl.no & Time $(\mathrm{sec})$ & Temp ( $\mathrm{C}) / \mathrm{Sp}-1$ \\
\hline 1 & $0-50$ & 24 \\
\hline 2 & $50-100$ & 24 \\
\hline 3 & $100-150$ & 24.5 \\
\hline 4 & $150-200$ & 24.5 \\
\hline 5 & $200-250$ & 24.8 \\
\hline 6 & $250-300$ & 30.6 \\
\hline & Fracture Load $(\mathrm{KN})$ & 15.1 \\
\hline
\end{tabular}

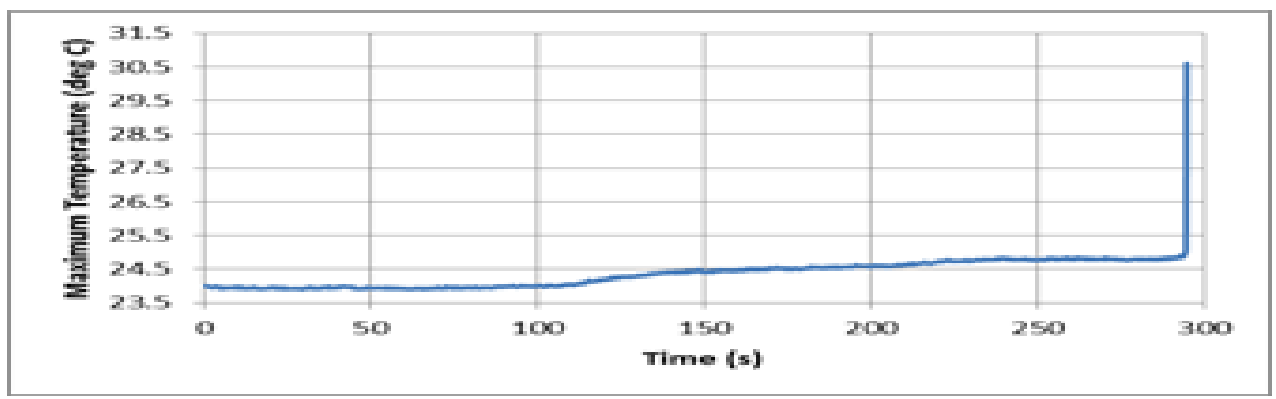

Fig: 12 Temperature Vs Time Failure load for complete time interval range of 0-294.6 sec

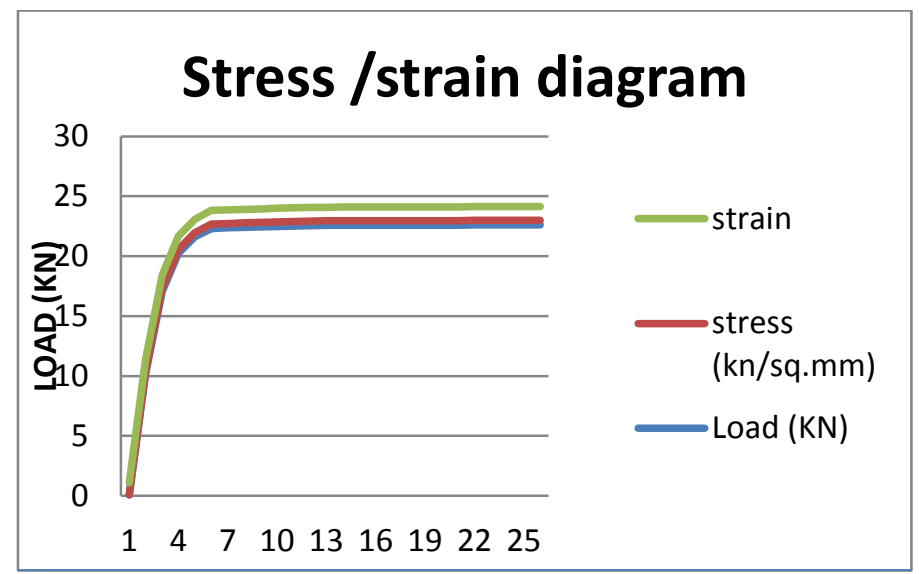

Fig:13. Stress vs strain diagram of Al/SiC specimen upto Failure load 
Table: 4. Summary of results between Stress vs Strain with Load

\begin{tabular}{|c|c|c|}
\hline Load (KN) & $\begin{array}{c}\text { Stress } \\
(K N / s q . m m) \\
\end{array}$ & strain \\
\hline 0.084803 & 0 & 1 \\
\hline 10.13189 & 0.17 & 1.04 \\
\hline 17.05153 & 0.28 & 1.07 \\
\hline 20.23642 & 0.34 & 1.08 \\
\hline 21.58848 & 0.36 & 1.1 \\
\hline 22.30041 & 0.37 & 1.16 \\
\hline 22.35307 & 0.37 & 1.13 \\
\hline 22.403 & 0.37 & 1.13 \\
\hline 22.4454 & 0.37 & 1.13 \\
\hline 22.48028 & 0.37 & 1.14 \\
\hline 22.51721 & 0.38 & 1.14 \\
\hline 22.5473 & 0.38 & 1.14 \\
\hline 22.56303 & 0.38 & 1.14 \\
\hline 22.57807 & 0.38 & 1.15 \\
\hline 22.58013 & 0.38 & 1.14 \\
\hline 22.58149 & 0.38 & 1.15 \\
\hline 22.58354 & 0.38 & 1.15 \\
\hline 22.58491 & 0.38 & 1.15 \\
\hline 22.58765 & 0.38 & 1.15 \\
\hline 22.59038 & 0.38 & 1.14 \\
\hline 22.5938 & 0.38 & 1.15 \\
\hline 22.60269 & 0.38 & 1.15 \\
\hline 22.60269 & 0.38 & 1.15 \\
\hline 22.60338 & 0.38 & 1.15 \\
\hline 22.60543 & 0.38 & 1.15 \\
\hline 22.60817 & 0.38 & 1.15 \\
\hline
\end{tabular}

Table:5. Summary of results during tensile deformation testing with actual and Graphical method

\begin{tabular}{|c|c|c|c|c|}
\hline $\begin{array}{c}\text { Specimen } \\
\text { No. }\end{array}$ & $\begin{array}{c}\text { Maximum } \\
\text { Temperature } \\
\text { in failure } \\
(\mathrm{C})\end{array}$ & $\begin{array}{c}\text { Yield } \\
\text { Point } \\
(K N)\end{array}$ & $\begin{array}{c}\text { Ultimate } \\
\text { Tensile } \\
\text { Strength } \\
(K N)\end{array}$ & $\begin{array}{c}\text { Fracture } \\
\text { load } \\
(K N)\end{array}$ \\
\hline$S p-1$ & 30.06 & 21.2 & 22.6 & 15.1 \\
\hline
\end{tabular}

\section{Conclusion:}

This experimental result is concerned with the fracture behaviour of Al/SiC composites which are made with Silicon carbide particles reinforced with aluminum alloy. The use of infrared thermographs for on-line monitoring the different stages of tensile deformation and predicting the exact region of fracture with correct temperature was demonstrated. The non-destructive infrared thermographic method helps for the detection of fracture growth and also identifying the time. The obtained results provide strong support for infrared thermography as a viable non-destructive evaluation tool for fracture assessment of Al/SiC metal matrix composite material and characterize tensile deformation and visualise different stages of materials deformation When the specimen breaks, the temperature becomes high. The experimental result reveals that the ultimate temperature rise and the rate of temperature rise is concentrated at the point at which the strains is focussed more so as to the failure is expected to takes place.

\section{Acknowledgement:-}

Authors are thankful to Dr. B. Venkataraman, The Associate Director of RadioLogical Safety and Environment Group, Indira Gandhi Centre for Atomic Research, Kalpakkam for his valuable permission to use the experimental facility. The Authors are also thankful to Mr. B. Anandapadmanaban, Head, Quality Assurance Division, Radio Logical Safety and Environmental Group, Indira Gandhi Centre for Atomic Research, Kalpakkam for the encouragement and support. The Authors are also thankful to Mrs. M. Menaka, In-charge of Quality Assurance Division, Indira Gandhi Centre for Atomic Research, Kalpakkam for her valuable testing support to use the experimental facility. Authors are also thankful to Karpagam University, Coimbatore for the preparation of composites specimens by stir casting process. 


\section{References}

[1] American Society for Testing and Material, Annual Book of ASTM Standards, USA, 1999. ASTM International, 100 Barr Harbor Drive, PO Box C700, West Conshohocken, PA 19428-2959. United States (Page no 1 -14)

[2] Xavier P. V. Maldague, " Theory and practice of Infrared Technology for Non- Destructive Testing" , Vol.ISBN 0-471-18190-0, John Wiley \& Sons, INC, New york, United states of America. Year of publication- 2001 (Page no 1 -11)

[3] S. Maillard, J. Cadith, P. Bouteille, G. Legros, J. L. Bodnar, V. Detalle "Non-destructive Testing of Forged Metallic Materials by Active Infrared Thermography" Int J Thermography (2012) Vol. 33:19821988

[4] B.B. Lahiri, S. Bagavathiappan, R. Shunmugasundaram, John Philip, T. Jayakumar "Measurement of annular air-gap using active infrared thermography" Infrared Physics \& Technology Vol. 61 (2013) 192199

[5] B. Venkataraman, Baldev Raj and C. K. Mukophadyay, "Characterisation of Tensile Deformation through Infrared Imaging Technique", Journal of the Korean Society for Nondestructive testing, Vol.22, No.6 (2002.12)

[6] Y. Sahin "Preparation and some properties of SiC particle reinforced aluminium alloy composites" Department of Mechanical Education, Faculty of Technical Education, Gazi University, Ankara 06500, Turkey, Materials and Design 24 (2003) 671-679

[7] Sourav Kayala, R. Beherab, G.Sutradhara "Mechanical properties of the as-cast silicon carbide particulate reinforced Aluminium alloy Metal Matrix Composites" International Journal of Current Engineering and Technology, Vol.2, No.3 (Sept. 2012) ISSN 2277 - 4106

[8] D. Shan, H. Nayeb-Hashemi "Fatigue-life prediction of SiC aluminum composite using a Weibull model" NDT\&E International , Vol.32 (1999) , pp. 265-274

[9] B. Venkataraman, C. K. Mukophadyay and Baldev Raj "Prediction of tensile failure of 316 stainless steel using Infrared thermography ", Experimental techniques for Non-destructive testing, Vol.25, No.5 (2004) (35-38)

[10] Cesar San Martin, Carlos Torres, Daniela Esparza, Daniela Bonilla "Thermal diffusivity measurements of spherical samples using active infrared thermography" Infrared Physics \& Technology Vol.55 (2012) 469-474

[11] E.Z. Kordatos, D.G. Aggelis, T.E. Matikas "Monitoring mechanical damage in structural materials using complimentary NDE techniques based on thermography and acoustic emission" Composites: Part B Vol. 43 (2012) 2676-2686

[12] G. La Rosa , A. Risitano "Thermographic methodology for rapid determination of the fatigue limit of materials and mechanical components" International Journal of Fatigue 22 (2000) 65-73

[13] John Montesano, Habiba Bougherara, Zouheir Fawaz "Application of infrared thermography for the characterization of damage in braided carbon fiber reinforced polymer matrix composites" Composites: Part B Vol. 60 (2014) 137-143

[14] B.Venkatraman, M.Menaka, P.Kalyanasundram and Baldev Raj "Infrared Imaging-an Overview on its Multifarious Possibilities and applications in IGCAR" , Journal of Non-destructive Testing \& Evaluation , Vol.5, Issue 2 September (2006) (Page:54-67) 